\title{
Erratum to: Fournier's gangrene: a radiologic emergency
}

Tatiana Piedra, Eva Ruíz, Francisco José González, Javier Arnaiz, Pedro Lastra, Gerardo López-Rasines

Department of Radiology, Hospital Universitario Marqués de Valdecilla, Av. Valdecilla s/n, 39008 Santander, Cantabria, Spain

Erratum to: Abdom Imaging (2006) 31:500-502 DOI 10.1007/s00261-006-9035-X

This article was inadvertently published a second time under DOI: 10.1007/s00261-005-0260-5.

Official publication is under DOI: 10.1007/s00261-006-9035-x appearing in Abdom Imaging (2006) 31:410-416.

The online version of the original article can be found under doi:10.1007/s00261-006-9035-x.

Correspondence to: Tatiana Piedra; email: tatianapiedra@yahoo.es 